\title{
РАЗВИТИЕ ВЫНОСЛИВОСТИ НА ПРАКТИЧЕСКИХ ЗАНЯТИЯХ ПО БАСКЕТБОЛУ СО СТУДЕНТКАМИ ВУЗА
}

\section{DEVELOPMENT OF ENDURANCE IN PRACTICAL BASKETBALL CLASSES WITH UNIVERSITY STUDENTS}

A. Ermolaev

G. Sheiko

Summary:The article reveals the issues of improving the physical education of students and developing new scientifically based methodological approaches in the development of physical qualities. After the end of an intensive increase in physical activity in a series of classes, physical performance is increased and conditions are created when, against the background of low-intensity loads of subsequent classes, the effect is maintained for a relatively long time. The ability to achieve this effect in the physical education lesson system retains continuity in the progressive development of endurance quality and provides the opportunity to solve learning problems in lessons characterized mainly by low-intensity loads. At the same time, the solution of educational problems is combined in time with an increased level of physical efficiency.

Keywords: basketball, students, physical training, training, endurance.

$\mathrm{B}$ последнее время одним из перспективных направлений совершенствования физического воспитания студентов является разработка новых научно обоснованных методических подходов в развитии физических качеств.

Столь пристальное внимание специалистов к развитию выносливости может быть объяснено многими причинами и, в первую очередь, тем, что достижение высокого уровня её развития обуславливается расширением функциональных возможностей жизненно важных физиологических систем: дыхания, кровообращения, энергообмена; оказывает содействие совершенствованию и закреплению адаптационных свойств растущего организма, предопределяет успешность прохождения учебного материала учебной программы и выполнения основных нормативных требований.

Вместе с тем, несмотря на значительное количество научных исследований, проблемы развития выносливости требуют своего дальнейшего разрешения. Анализ научных данных выявляет здесь различные, а порой и противоречивые взгляды, отсутствие согласованности в единстве подходов к выбору состава педагогических средств и методов воздействия на развитие выносливости $[1,5]$.
Ермолаев Александр Петрович

старший преподаватель, Стерлитамакский филиал Башкирского государственного университета aleks479@mail.ru

Шейко Гузель Абдулхаковна

стариий преподаватель, Стерлитамакский филиал Башкирского государственного университета oksyk21@gmail.com

Аннотация: В статье раскрываются вопросы совершенствования физического воспитания студентов и разработки новых научно обоснованных методических подходов в развитии физических качеств. После прекращения интенсивного наращивания физических нагрузок в серии занятий, физическая работоспособность повышается и создаются условия, когда на фоне малоинтенсивных нагрузок последующих занятий достигнутый эффект сохраняется относительно долгое время. Возможность достижения этого эффекта в системе уроков физической культуры сохраняет преемственность в поступательном развитии качества выносливости и обеспечивает возможность решать задачи обучения на уроках, характеризующихся преимущественно малоинтенсивными нагрузками. При этом решение образовательных задач сочетается по времени с повышенным уровнем физической работоспособности.

Ключевые слова: баскетбол, студентки, физическая подготовка, обучение, выносливость.

Важным, но недостаточно решенным для практики физического воспитания остается вопрос нормирования физических нагрузок, их распределение в системе урочных форм занятий при решении различных педагогических задач, и в частности, сопряженных с обучением сложно-координационным двигательным действиям, включая спортивные игры. Как правило, в большинстве исследований рассматривается преимущественно либо процесс обучения двигательным действиям, либо процесс развития физических качеств. Это снижает продуктивность учебно- воспитательного процесса в целом, не позволяет отдельно разработанные методические подходы эффективно увязывать в его структуре, согласовывать с конкретным содержанием тематических разделов учебной программы по физической культуре [2,3]. Также в проанализированных нами работах не было обнаружено достаточно данных по вопросам планирования учебного материала, возможности развития выносливости на образовательных уроках, обеспечения непрерывности процесса повышения двигательной подготовленности студенток первокурсниц в системе образовательных практических занятий. Обозначенные вопросы, имеющие большое практическое значение при решении задач совершенствования физического воспитания, требуют научно обоснованного решения и обуславливают актуальность выбранной темы исследования. 
Цель исследования. На основе закономерностей динамики физической работоспособности разработать методику развития выносливости студенток 1 курса на практических занятиях по баскетболу.

В соответствии с целью исследования решались следующие задачи:

1. Исследовать структуру и содержание образовательных практических занятий по баскетболу в ВУЗе, выявить эффективность их влияния на развитие физической подготовленности студенток первокурсниц.

2. Определить в динамике учебного процесса влияние различных по направленности, объему и интенсивности физических нагрузок на работоспособность студенток 1 курса.

3. Изучить динамику физических способностей у студенток первокурсниц для уточнения направленности, объема и интенсивности педагогических средств воздействия на развитие выносливости.

4. Разработать экспериментальную методику развития выносливости у студенток 1 курса на практических занятиях по баскетболу, проверить её эффективность.

В исследовании были применены следующие методы исследования:

1. Анализ спортивно-педагогической литературы использовался для изучения состояния вопроса в педагогической теории и практике.

2. Метод педагогических наблюдений проводился для выявления структуры и содержания практических занятий по баскетболу со студентками вуза.

3. Метод пульсометрии проводился для выявления индивидуальных норм физической нагрузки, базирующейся на реакции сердечно-сосудистой системы (ЧСС).

4. Метод хронометрирования проводился для определения моторной плотности практического занятия и процентного содержания времени, отводимого на обучение и развитие физических качеств.

5. Метод педагогического тестирования проводился с целью изучения двигательной и технической подготовленности студенток.

6. Математическая обработка полученных значений проводилась для статистического анализа.

На основе анализа педагогических наблюдений, хронометрирования практических занятий и оценки двигательной подготовленности студенток первокурсниц было сделано заключение о том, что в целостном учебно-воспитательном процессе использование образовательных уроков по баскетболу, планируемых в соответствии с существующими методическими рекомендациями, дает возможность занимающимся успешно осваивать программный материал обучения двигательным действиям, но не обеспечивает прогрессивной динамики в развитии основных физических качеств, включая и качество выносливости. Образовательная направленность уроков выражается тем, что около 70\% студенток осваивают технику двигательных действий на «хорошо» и «отлично».

В основу работы, позволяющей реализовать выработанные методические требования совершенствования учебно-воспитательного процесса студенток первокурсниц, был положен принцип волнообразного изменения физических нагрузок, широко используемый в практике спортивной подготовки. В соответствии с положениями этого принципа после прекращения интенсивного наращивания физических нагрузок в серии занятий, физическая работоспособность повышается и создаются условия, когда на фоне малоинтенсивных нагрузок последующих занятий достигнутый эффект сохраняется относительно долгое время. Возможность достижения этого эффекта в системе уроков физической культуры сохранила бы преемственность в поступательном развитии качества выносливости и обеспечила бы возможность решать задачи обучения на уроках, характеризующихся преимущественно малоинтенсивными нагрузками. При этом решение образовательных задач должно сочетаться по времени с повышенным уровнем физической работоспособности.

Из специальной литературы известно, что наиболее эффективно на динамику работоспособности можно воздействовать через процесс развития тех физических качеств, прирост показателей которых обуславливается выполнением двигательных действий в режиме развивающего утомления. К числу таковых относятся скоростно-силовые качества и выносливость [4].

Изучение показателей развития этих качеств позволило определить состав педагогических средств воздействия на организм девушек студенток. Полученные данные выявили относительно невысокие показатели выносливости и скоростно-силовых качеств. При этом, результаты тестов (табл. 1), характеризующих данные физические качества, подтвердили мнение о том, что при общей положительной тенденции величины прироста в различных тестах неодинаковы, и это обуславливается спецификой структурной организации взаимодействия мышечных групп и систем организма, различиями их функциональной активности, определяемой содержанием конкретного тестового упражнения.

Полученные результаты особенностей развития физических способностей студенток первокурсниц были использованы для выяснения возможностей влиять на 
Показатели физической подготовленности в исследуемых группах (КГ и ЭГ) до начала педагогического эксперимента

\begin{tabular}{|c|c|c|c|c|}
\hline \multirow[b]{2}{*}{ Виды контрольных испытаний(тесты) } & \multicolumn{2}{|c|}{ КГ (26 чел.) } & \multicolumn{2}{|c|}{ ЭГ (24 чел.) } \\
\hline & $\begin{array}{c}\text { Исходный уровень } \\
\mathrm{g} \pm \mathrm{m}\end{array}$ & $\begin{array}{c}\text { P } \\
\text { (достоверность различий) }\end{array}$ & $\begin{array}{c}\text { Исходный уровень } \\
\mathrm{g} \pm \mathrm{m}\end{array}$ & $\begin{array}{c}\text { P } \\
\text { (достоверность различий) }\end{array}$ \\
\hline Выпрыгивание вверх с места, см & $19 \pm 2,2$ & $>0,05$ & $19 \pm 2,4$ & $>0,05$ \\
\hline Прыжок в длину с места, см & $168 \pm 1,3$ & $>0,05$ & $169 \pm 1,2$ & $>0,05$ \\
\hline Бег $3 \times 10 \mathrm{M}$, сек & $10,6 \pm 0,9$ & $>0,05$ & $10,5 \pm 0,7$ & $>0,05$ \\
\hline Бег 5 мин, м & $1074 \pm 14,4$ & $>0,05$ & $1075 \pm 12,1$ & $>0,05$ \\
\hline Бег 1,5 мин, $\mathrm{M}$ & $308 \pm 3,1$ & $>0,05$ & $307 \pm 2,9$ & $>0,05$ \\
\hline $\mathrm{PWC}_{170^{\circ}}$ кгм/мин & $10,1 \pm 0,3$ & $>0,05$ & $10,0 \pm 0,2$ & $>0,05$ \\
\hline
\end{tabular}

динамику физической работоспособности девушек в процессе занятий физическими упражнениями.

В педагогическом эксперименте в состав «неспецифических» упражнений включались преимущественно упражнения скоростно-силового характера, выполняемые в режиме развития выносливости, то есть до определенных стадий утомления. Чтобы обеспечить большой объем выполнения неспецифических упражнений на практическом занятии, они подразделялись на локализации мышечных напряжений; упражнения локального характера воздействия, где работа обеспечивалась отдельными относительно небольшими группами мышц; регионального характера с подключением к работе больших мышечных групп; комплексного характера, когда в работе принимают участие практически все основные мышечные группы. Выведение «неспецифических» по отношению к процессу обучения баскетболу упражнений, по выше перечисленным признакам облегчало возможность регулировать кумулятивный эффект как в отдельно взятом уроке, так и в системе урочных занятий. Во-первых, локальное воздействие на отдельные мышечные группы создавало условия, когда при поточном выполнении упражнений одна группа мышц расходовала свой потенциал, другая его восстанавливала. Во-вторых, разнообразие упражнений с сохраняющейся единой тренирующей направленностью обеспечивало разнообразие содержания уроков и вызывало значительное повышение функциональной активности организма студенток и относительно длительное поддержание достигнутого уровня. В-третьих, в зависимости от функционального состояния организма студенток первокурсниц представлялась возможность оперативно реагировать на его реакцию и перераспределять состав упражнений. Опробование возможности воздействовать на динамику физической работоспособности проводилось в системе взаимосвязанных уроков физической культуры посредством интенсивного наращивания объема «неспецифических» упражнений. Результаты исследования показали, что повышение нагрузок в течение 8 уроков обусловливается снижением показателей физической работоспособности девушек в среднем на 10-13\% по сравнению с исходными данными. Последующее снижение нагрузок вызывает восстановление и дальнейшее увеличение показателей работоспособности в среднем на 6-10\%. При этом фаза повышенной работоспособности у студенток удерживается в зависимости от физической подготовленности в среднем до двух недель. На основе этих данных уточнена динамика повышения нагрузки, соотношение объема и интенсивности «неспецифических» упражнений, как в отдельных уроках, так и в системе урочных занятий; выявлены режимы деятельности сердечно-сосудистой системы, определяющей необходимый уровень дозировки нагрузок.

Применение волнообразной динамики повышения физических нагрузок обусловило необходимость выделения в экспериментальном учебно- воспитательном процессе четырех микроциклов по четыре урока в каждом. Выбранная структура облегчает создание преемственности в направленности использования средств воздействия, как между отдельными уроками, так и более крупными их образованиями, объединенными содержанием и логикой решения педагогических задач.

В первом микроцикле преимущественно решаются задачи обучения двигательным действиям. Соответственно этому на «специфические» упражнения (основные, подготовительные и подводящие) отводится 45-50\% времени урока. На «неспецифические» упражнения (представленные комплексами общеразвивающих упражнений скоростно-силовой направленности) выделяется 20\% времени, и они включаются в содержание уроков после решения задач обучения. В процессе обучения, осваиваемые двигательные действия предъявляются студенткам к овладению в соответствии с закономерностями этапного формирования двигательного навыка и требованиями принципа постепенного повышения требований. Анализ функциональных реакций организма первокурсниц по показателю частоты сер- 
дечных сокращений свидетельствует, что тренирующие воздействие на данных уроках носят «поддерживающий» характер оптимального функционального состояния организма. Средняя ЧСС в основной части урока составляет в среднем 120- 130 уд/мин.

Во втором микроцикле соотношение «специфических» и «неспецифических» упражнений сохраняется. Однако в структуре образовательного процесса увеличивается время на совершенствование освоенных двигательных действий, увеличивается интенсивность выполнения упражнений, сокращаются интервалы отдыха. Все это приводит к значительной активизации в деятельности сердечно-сосудистой системы. По данным регистрации ЧСС при совершенствовании двигательных действий данный показатель увеличивается у студенток до 160-165 уд/мин. Последующее после совершенствования двигательных действий включение «неспецифических» упражнений позволяет сохранять, а в отдельных случаях и увеличивать достигнутый уровень функциональной активности организма, поддерживаемая длительное время упражнениями «специфического» и «неспецифического» характера, создает условие для начала формирования тренирующей направленности педагогических воздействий и возможность управлять динамикой физической работоспособности.

В третьем микроцикле процесс обучения двигательным действиям заканчивается, и он представлен только этапом совершенствования. Соотношение «специфических» и «неспецифических» упражнений изменяется. На долю первых приходится менее $20 \%$ общего бюджета времени урока. В этом же цикле изменяется и последовательность использования упражнений. Специфические упражнения, которые представлены разученными двигательными действиями, выполняются студентками после комплекса «неспецифических» упражнений.

Перераспределение «специфических» и «неспецифических» упражнений в структуре уроков третьего микроцикла ведет к существенному повышению уровня
чСС, который начинает увеличиваться с первых минут основной части уроков, а затем поддерживается в границах 170-175 уд/мин. если учесть, что средняя моторная плотность уроков достигает $60-65 \%$, то становится ясным высокий тренировочный эффект уроков третьего микроцикла.

В четвертом микроцикле решалась одна задача - воздействие на развитие выносливости. Его специфической особенностью является включение в состав «неспецифических» упражнений равномерного бега. Объем времени выполнения беговых нагрузок на каждом уроке для студенток составляет 8 минут (4 мин. х 2). Беговые нагрузки в уроке сочетались со скоростно-силовыми упражнениями и двусторонней игрой в баскетбол. Анализ динамики ЧСС, регистрируемой на этих уроках, свидетельствует о высокой функциональной активности организма студенток в процессе занятий. Средние максимальные величины чСС доходили до уровня 180190 уд/мин., что свидетельствует о значимости средств воздействий, предъявляемых студенткам на уроках 4-го микроцикла.

Эффективность апробированной методики оценивалась по результатам развития выносливости, а также параметрам скоростно-силовых качеств и успешности овладения техникой двигательных действий игры в баскетбол. Данные экспериментальной группы сравнивались с таковыми контрольной группы (табл. 2).

Наибольшие сдвиги отмечаются у студенток при выполнении нагрузок в режиме субмаксимальной и большой мощности.

Показатели скоростно-силовых качеств за период апробации существенно превысили свои исходные значения, по сравнению с контрольной группой студентки экспериментальной группы намного опередили своих сверстников по показателям физической подготовленности. В то же время результаты экспертных оценок по технике выполнения разученных двигательных дей-

Таблица 2.

Показатели физической подготовленности в исследуемых группах (КГ и ЭГ) после педагогического эксперимента

\begin{tabular}{|c|c|c|c|c|}
\hline \multirow{2}{*}{$\begin{array}{l}\text { Виды контрольных } \\
\text { испытаний(тесты) }\end{array}$} & \multicolumn{2}{|c|}{ КГ (26 чел.) } & \multicolumn{2}{|c|}{ ЭГ (24 чел.) } \\
\hline & $\begin{array}{c}\text { Исходный уровень } \\
\mathrm{g} \pm \mathrm{m}\end{array}$ & $\begin{array}{c}\text { P } \\
\text { (достоверность различий) }\end{array}$ & $\begin{array}{c}\text { Исходный уровень } \\
\mathrm{g} \pm \mathrm{m}\end{array}$ & $\begin{array}{c}P \\
\text { (достоверность различий) }\end{array}$ \\
\hline $\begin{array}{l}\text { Выпрыгивание вверх с ме- } \\
\text { ста, см }\end{array}$ & $23 \pm 2,1$ & $>0,05$ & $28 \pm 2,4$ & $>0,05$ \\
\hline Прыжок в длину с места, см & $174 \pm 1,2$ & $>0,05$ & $178 \pm 1,3$ & $>0,05$ \\
\hline Бег 3 x 10м, сек & $9,5 \pm 0,9$ & $>0,05$ & $8,8 \pm 0,7$ & $>0,05$ \\
\hline Бег 5 мин, м & $1078 \pm 10,1$ & $>0,05$ & $1115 \pm 12,3$ & $>0,05$ \\
\hline Бег 1,5 мин, м & $312 \pm 2,1$ & $>0,05$ & $358 \pm 2,1$ & $>0,05$ \\
\hline $\mathrm{PWC}_{170^{\prime}}$ кгм/мин & $10,5 \pm 0,3$ & $>0,05$ & $12,6 \pm 0,2$ & $>0,05$ \\
\hline
\end{tabular}


Таблица 3.

Результаты экспертной оценки овладения техническими приемами баскетбола в контрольной и экспериментальной группах (в \%)

\begin{tabular}{|c|c|c|}
\hline $\begin{array}{c}\text { Оценка освоения основных элементов } \\
\text { техники баскетбола }\end{array}$ & КГ (26 чел.) & ЭГ (24 чел.) \\
\hline отлично & 23 & 25 \\
\hline хорошо & 61,5 & 66,7 \\
\hline удовлетворительно & 15,5 & 8,3 \\
\hline
\end{tabular}

ствий были близки у студенток обеих групп, что свидетельствует о возможности качественно решать задачи обучения в структуре предложенной экспериментальной методики развития выносливости у студенток первокурсниц(табл.3).

Анализируя полученные данные можно отметить, что совершенствование освоенных новых двигательных действий на фоне развивающего утомления обуславливает у студенток надежность в сформированности двигательных навыков, их высокую устойчивость и вариативность в игровой деятельности. По итогам экспертной оценки в экспериментальной группе владение техникой двигательных действий игры в баскетбол на «отлично» и «хорошо» демонстрировало 91,7\% занимающихся.

В ходе педагогического эксперимента установлено, что развитие выносливости в единстве с обучением новым двигательным действиям игры в баскетбол достигается на практических занятиях по дисциплине физическая культура при условии распределения учебного материала в соответствии с закономерностями фазного изменения физической работоспособности, где процесс обучения приходится на фазу повышенной работоспособности, формирующейся предшествующей системой взаимосвязанных уроков.

Установлено, что процесс совершенствования освоенных двигательных действий игры баскетбол может выполнить две относительно самостоятельных функции. Первая определяется решением задач по закреплению техники двигательного действия и повышению её надежности в игровых условиях. Вторая - использование разученных двигательных действий в качестве средств расширения функциональных возможностей дыхания и кровообращения как ведущих систем в проявлении выносливости (получение дополнительного тренировочного эффекта). Единство реализации этих двух функций становится возможным при условии включения в уроки процесса совершенствования двигательных действий вслед за процессом развития выносливости, то есть в условиях развивающегося утомления. При решении первой группы задач частота сердечных сокращений выходит на уровень 155-160 уд/мин. при решении задач второй группы - соответственно 170-180 уд/мин.

\section{ЛИТЕРАТУРА}

1. Аракчеев Д.А. Развитие двигательных способностей у студентов посредством игры в баскетбол / Аракчеев Д.А., Зуева И.А. // «Молодежный научный форум: гуманитарные науки»: матер. XV студенческой международной заочной научно-практической конференции (август 2014г) - С.55-61.

2. Галкин А.Р. Баскетбол как средство развития двигательных способностей у студентов. Физкультура и спорт: актуальные аспекты науки и практики VII Международная студенческая научная конференция (г. Москва, май 2015 г.). - С.5 - 7.

3. Нестеровский, Д.И. Баскетбол: теория и методика обучения: учеб. пособие для студентов высш. пед. учеб. заведений / Д.И. Нестеровский. - М.: Издательский центр «Академия», 2004. - 336 с.

4. Соколов А.М. Подготовка баскетболистов массовых разрядов в вузах с учетом особенностей физического развития студентов: [Текст] / А.М. Соколов. Москва, 2013. - 137 c.

5. Ц Церковная Ф.В. Баскетбол как средство развития выносливости и психофизиологических способностей студентов технических вузов./ Е.В. Церковная // Физическое воспитание студентов творческих специальностей - 2015 - №1. - С. 157-161. 